\title{
Solid Oxide Fuel Cell Technology Stationary Power Application Project
}

\author{
Final Report
}

DOE Co-Operative Agreement No. DE-FC26-06NT42810

Reporting Period:

September 2006 - March 2009

Prepared for

National Energy Technology Laboratory

U. S. Department of Energy

by

Siemens Energy, Inc.

Stationary Fuel Cells Division

George Westinghouse Science \& Technology Center

1310 Beulah Road

Pittsburgh, PA 15235-5098

Project Manager: Joseph F. Pierre

July 2009 


\section{DISCLAIMER}

This report was prepared as an account of work sponsored by an agency of the United States Government. Neither the United States Government nor any agency thereof, nor any of their employees, makes any warranty, express or implied, or assumes any legal liability or responsibility for the accuracy, completeness, or usefulness of any information, apparatus, product, or process disclosed, or represents that its use would not infringe privately owned rights. Reference herein to any specific commercial product, process or service by trade name, trademark, manufacturer, or otherwise does not necessarily constitute or imply its endorsement, recommendation, or favoring by the United States Government or any agency thereof. The views and opinions of authors expressed herein do not necessarily state or reflect those of the United States Government or any agency thereof. 


\begin{abstract}
The objectives of this program were to:

- Develop a reliable, cost-effective, and production-friendly technique to apply the powerenhancing layer at the interface of the air electrode and electrolyte of the Siemens SOFC

- Design, build, install, and operate in the field two $5 \mathrm{kWe}$ SOFC systems fabricated with the state-of-the-art cylindrical, tubular cell and bundle technology and incorporating advanced module design features.
\end{abstract}

Siemens successfully demonstrated, first in a number of single cell tests and subsequently in a 48-cell bundle test, a significant power enhancement by employing a power-enhancing composite interlayer at the interface between the air electrode and electrolyte. While successful from a cell power enhancement perspective, the interlayer application process was not suitable for mass manufacturing. The application process was of inconsistent quality, labor intensive, and did not have an acceptable yield.

This program evaluated the technical feasibility of four interlayer application techniques. The candidate techniques were selected based on their potential to achieve the technical requirements of the interlayer, to minimize costs (both labor and material), and suitably for large-scale manufacturing. Preliminary screening, utilizing lessons learned in manufacturing tubular cells, narrowed the candidate processes to two, ink-roller coating (IRC) and dip coating (DC). Prototype fixtures were successfully built and utilized to further evaluate the two candidate processes for applying the interlayer to the high power density Delta8 cell geometry. The electrical performance of interlayer cells manufactured via the candidate processes was validated. Dip coating was eventually selected as the application technique of choice for applying the interlayer to the high power Delta8 cell. The technical readiness of the DC process and product quality was successfully and repeatedly demonstrated, and its throughput and cost are amenable to large scale manufacturing.

Two $5 \mathrm{kWe}$-class SOFC power systems were built and installed for the purpose of testing and evaluating state-of-the-art tubular cell and bundle technologies, advanced generator and module design features, balance-of-plant components, and cost reduction measures. Installed at the Phipps Conservatory and Botanical Gardens, a system operated for more than 17,500 hrs, delivering electrical power to the on-site grid and thermal energy in form of hot water for onsite utilization. Operation was typically autonomous, requiring minimal operator intervention, and achieved an overall availability of greater than $85 \%$. Outages were primarily due to an unstable local grid, two weather related outages were experienced, and very few reliability issues were encountered despite harsh operating conditions. No repairs to the stack, module, or balance-of-plant were required. A second system was designed, built, delivered, and installed at a Siemens facility in Charlotte, North Carolina. Operational issues associated with the balance-of-plant were encountered during startup and prevented the system from operating. 


\section{TABLE OF CONTENTS}

PAGE

TASK 1 - DEVELOPMENT OF AN INTERLAYER APPLICATION TECHNIQUE FOR HPD SOFC ......... 1

TASK 1.1 - FEASIBILITY STUDY OF APPLICATION TECHNIQUES ........................................................... 1

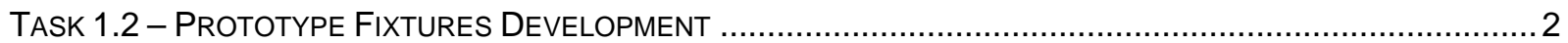

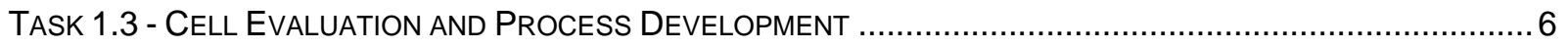

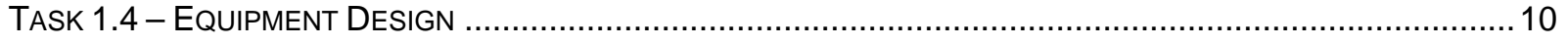

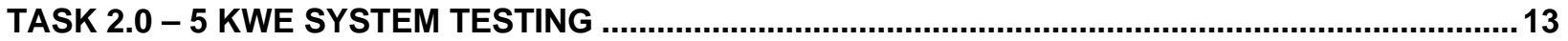

TASK 2.1 - 5 KWE SYSTEM ASSEMBLY - NORTH CAROLINA ................................................................. 13

TASK 2.2 - 5 kWE INSTALLATION, StARTUP AND OPERATION - NORTH CAROLINA ...................................... 14

TASK 2.3 - 5 KWE INSTALLATION, STARTUP, AND OPERATION - PHIPPS CONSERVATORY AND BOTANICAL

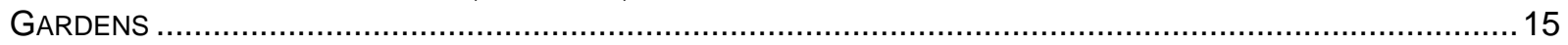

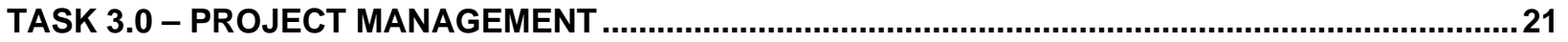

\section{LIST OF FIGURES}

PAGE

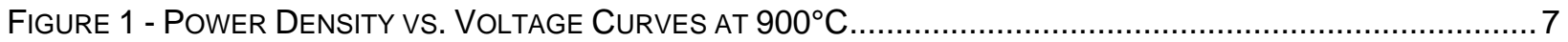

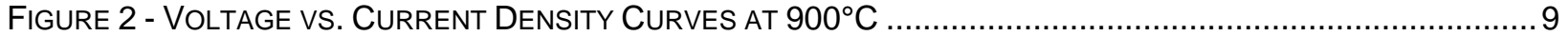

FigURE 3 - Roller CoATING MACHINE FOR APPLYING INTERLAYER TO DELTA8 CELLS ................................. 9

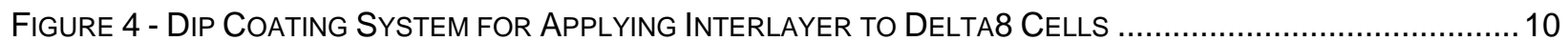

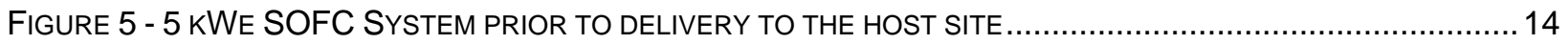

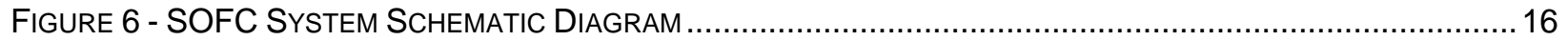

FigURE 7 - THE 5 KWE-CLASS SOFC POWER SYSTEM INSTALLED AT THE PHIPPS CONSERVATORY .................. 17

FIGURE 8 - LIFETIME PLOT OF THE PHIPPS SFC-5 SOFC SYSTEM ..................................................... 18

\section{LIST OF TABLES}

PAGE

TABle 1 - Phipps 5 kWe SOFC Power System Performance Summary AS of MARCH 31, 2009 ............. 18

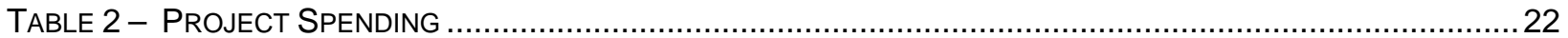

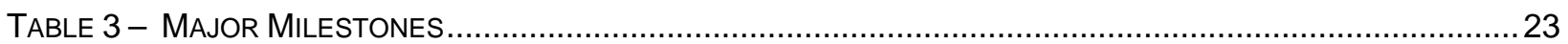




\section{Task 1 - Development of an Interlayer Application Technique for HPD SOFC}

\section{TASK 1.1 - FEASIBILITY STUDY OF APPLICATION TECHNIQUES}

Approach: A successful operation of fuel cells relies upon a fast and effective transport of oxygen molecules/ions through all functional layers as well as their interfaces. This is of particular importance at the cathode and electrolyte interface where the transformation of oxygen molecules to ions takes place. While an interlayer material that meets its functional requirement has been successfully identified, it is crucial to develop a technique that can be used to apply this interlayer in a cost-effective manner. The objective of this task was to expedite the development of an interlayer application technique for high-power-density (HPD) cells by utilizing our past experience that was built upon the tubular cells. The approach taken was to first evaluate the technical feasibility of four application techniques, in parallel, on tubular cells. The techniques to be evaluated were ones that offered the best potential to achieve the technical requirements of the interlayer, to minimize costs (both labor and material), and to be amenable to large scale manufacturing. Once the feasibility of the techniques was demonstrated, those which had the greatest likelihood of success for the HPD cells were studied further.

Results and Discussion: The interlayer application techniques were investigated using tubular cells to reveal any potential technical challenges that may be encountered when they are applied to the HPD cells. The candidate techniques that have been extensively studied in this project included vacuum infiltration, atmospheric plasma spray, wet power spray, ink roller coating, and dip coating. Each one of them was rigorously examined with respect to the following criteria. Firstly, an appropriate adhesion between the interlayer and its substrate, which is needed to survive the subsequent plasma spray processes, was a must. This was determined by applying the interlayer, plasma spraying the electrolyte (under standard plasma spray conditions) onto the interlayer, and visual inspection of the end product. Results showed that strong interfacial bonding was an innate characteristic for some techniques, e.g., plasma spray, but was only achievable by additional treatment for others.

Secondly, maintaining the desirable porosity and chemistry, which ultimately determines the magnitude of power enhancement, was an equally important screening criterion. To assure no compromise in interlayer functionality, microstructure analysis and impedance tests were performed on sample cells prepared by various techniques. Again, some techniques, e.g., ink roller coating, readily met this criterion while with other techniques it was found to be extremely difficult to control the porosity and chemistry. 
Lastly, although there were unique pros and cons associated with each technique, a common issue among all techniques was also identified. The application technique and the presence of interlayer itself could adversely affect the quality of other cell components, in particular the electrolyte layer, resulting in a porous, leaky cell. To ensure the acceptability of the interlayer application technique, the molecular leak rate of the densified electrolyte was used as the final screening criterion. Interestingly, it was found that the edge of the interconnection was the area most prone to leaking regardless of the application technique used. However, the best solution to resolve this issue varied significantly from technique to technique. More importantly, due to the difference in geometry dependence, some techniques which required no contact between the applicator and parts, e.g., dip coating, were likely to be more forgiving when the HPD cells are in play.

Conclusion: Two interlayer application techniques were successfully identified for further development for the HPD cells. The ink-roller-coating (IRC) was selected based on its proven success and technical maturity. The dip coating (DC) process was also selected in view of its great potential for mass production and cost reduction.

\section{TASK 1.2 - PROTOTYPE FIXTURES DEVELOPMENT}

Approach: Ink-roller-coating (IRC) and dip coating (DC) were selected as the two target techniques to be further evaluated for applying the composite interlayer (CIL) to the highpower-density (HPD) cells. (Note CIL is a mixture of cathode and electrolyte materials.) The HPD of interest was the Delta8 cell, which represents the cell design for the next generation system. The objective of this task was to validate these selected application techniques in a pilot environment. Prototype fixtures were designed, fabricated, and used to prepare production-quality HPD cells for electrical performance evaluation. For IRC, the capital investment of such a fixture is significant; therefore the most costeffective approach was to work with a vendor that is capable of adapting its existing technique to suit our special needs. For DC, on the other hand, a home-made fixture was constructed at a relatively low cost and would allow for quicker turnaround. In addition to the above tasks, parallel efforts to identify the optimal post-coating process conditions, such as drying and calcination, were also addressed. Microanalyses were performed on multiple samples to ensure in-specification properties and microstructure.

\section{Results and Discussion:}

Ink-Roller Coating (IRC) has been selected as the primary technique to apply the CIL for tubular cells. In this configuration, the air electrode (AE) tube is placed on a "hot dog roller" type of system and rotates continuously to pick up the coating material from the rollers that are saturated with ink. In spite of its proven feasibility and consistency, it cannot be directly applied to the HPD cells due to the differences in geometry. The direct roll coating (DRC) process, which employs the same concept and has been extensively used in other industries for applying thin coatings, shows great potential for applying the CIL to the HPD cells. In this case, the rollers are positioned perpendicular, instead of parallel, to the long-axis of the substrate. The substrate is placed in a stationary position, instead of rotating, on a powered conveyor to move through the predetermined gap between the process and bottom rollers. The DRC rollers and the conveyer (and thus the substrate) run continuously. The process roller and the doctor roller, along with sidewalls called dam plates, form a small reservoir that contains an ink- 
like coating material. The distance and relative speeds between the process and doctor rollers serve to meter the desired quantity of ink onto the process roller. This ink is then ready to be deposited onto the substrate. As it is conveyed to the machine and enters the nip (the gap between the process and bottom roller), contact with the process roller directly transfers the ink to the substrate and forms a coating.

Since DRC functions by metering the correct amount of coating material onto a process roller that subsequently applies this material onto the substrate, several benefits can be realized from using it for CIL application. Firstly, there is no excess material applied that needs be removed. Therefore, it has very high transfer efficiency and little of the costly CIL material is lost. Secondly, the application is completed in one pass through the DRC and no repetitive coating is needed. Thirdly, DRC is very robust as long as the coating material level, the gaps between the rollers and the roller speed are monitored and maintained. Thus, after initial equipment set up, few changes are required for the subsequent applications to maintain a coating with consistent quality.

There are two key technical challenges for DRC to be successful. First, since the process roller was machined according to the Delta8 air AE drawing, any bow in the lateral axis of the actual $\mathrm{AE}$ may cause cracking due to the compressive stress while passing through the nip. Second, the coating mechanism solely relies on the intimate contact between the roller and the AE. Therefore, any geometrical irregularities of the $\mathrm{AE}$, such as warp and depression, may result in areas that are not coated. To address these potential issues, the approach taken was to use soft process and bottom rollers to minimize mechanical damage to the $A E$ as well as to accommodate geometry variations.

A series of trials were conducted at the vendor site. The first one consisted of coating the Delta side as well as the flat side of a Delta8 aluminum standard model to establish the process parameters for coating actual Delta8 cells. The ultimate goal was to determine the combination of the process settings, which would produce the target interlayer weight. The key process settings include:

- Vertical Adjustment - Dial setting which controls vertical positioning pressure of the coating roller on the Delta8 cell as well as coating film thickness.

- Doctor Roller Adjustment - Dial setting which controls the flow of ink to the coating roller and subsequently to the Delta8 cell.

- Roller Speed - Dial setting which controls the speed of the Delta8 cell through the horizontal roller coating machine as well as final coating weight.

Three runs were conducted on the delta side as well as one run on the flat side of the aluminum standard model. Pickup weights were measured to establish the process parameter settings which were used to run the second series of trials in which four Delta8 sections were coated, dried, and weighed. After the first run of this series, the Vertical Adjustment parameter was decreased due to the lower-than-expected weight pickup.

This change successfully brought the weight pickup back to the target range during the subsequent runs. In the third series of trials, three runs were conducted to coat two fullsize Delta8 AE. The process parameters established during the second series of trials were used and the interconnection areas (on the flat side) were masked prior to coating. 
The delta sides of both AE were coated first but, unfortunately, both were broken during the run.

Post-test examination revealed crucial information for improvement. Firstly, the table that supported the AE before coating was found to be slightly higher than the table following the coating process. As a result, the AE was actually held in a cantilever position during the entire coating process. In this case, the hanging arm, and thus the bending moment, continued to increase as the $A E$ went through the rollers. Therefore, it is not surprising that a critical stress limit was eventually reached, causing the first AE to fracture. It is believed that this issue can be readily addressed by adjusting the height of the table. Secondly, because the process roller matches the Delta side like gears, there is no degree of freedom for any lateral motion. In other words, the long axis of AE must be kept perpendicular to that of the roller during the entire coating process to prevent any lateral bending. Unfortunately, there is no such mechanism to ensure this for the current setup. It is believed that the fracture of the second $A E$ was due to the misaligned manual feed at the beginning of the coating process. Similarly, this issue can be readily addressed by adding a guiding fence, which is perpendicular to the roller axis, to the coating table. Thirdly, examination of the dried interlayer coating revealed that not all surface areas in any of the runs were fully coated. Furthermore, the uncoated areas generally coincided with the preexisting surface irregularities such as depression and warp on both the delta and flat sides. In this case, loss of close contact would naturally create the uncoated areas. One possible remedy is to use an even softer rubber for the process roller. Minor variation in geometry can be more effectively accommodated by the roller's higher compliance.

Despite the above setback, one Delta8 cell which has an interlayer applied manually by the same roller coating technique was submitted for electrical testing. The result of this test can be used as the baseline for projecting the electrical performance of cells with interlayer applied by DRC.

Dip Coating (DC) was the other technique being evaluated for applying the CIL onto HPD cells. In general, DC requires soaking the substrate for a specified amount of time in slurry of specified composition and characteristics, and then removing it from the slurry at a controlled rate. Although all these factors need to be clearly defined in order to develop a robust and capable process, it is one of the most straightforward coating techniques. In addition, it also has the following advantages over the DRC process:

- Since there is no media involved, i.e., no mechanical contact with the substrate, DC is robust to any variation in substrate geometry. Bowing in any axis, for example, will not affect the coating quality and there will be no risk of damage to the substrate due to mechanical contact.

- The slurry used is alcohol-based and yields a very quick drying rate. This not only enables the elimination of a physical drying process but also minimizes the time allowed for slurry to run.

- DC has high transfer efficiencies with little collateral losses of coating material, resulting in a cost-effective and clean process. 
In contrast to the advantages, there are also several technical challenges to be addressed for DC:

- Maintaining proper solids suspension as well as the specified solids levels throughout the slurry dipping vessel.

- Solvent penetration into the substrate.

- Since the whole substrate is submerged, a physical mask must be applied to the interconnection (IC) area, potentially providing a preferred route for slurry to run.

In order to demonstrate the aforementioned advantages and address those potential challenges, our approach was to build an in-house DC test stand that consists of a dipping reservoir, a slurry circulation system, and a substrate conveyor system so that any modification can be implemented in a timely fashion.

For DC, the quality of interlayer can be greatly affected by both the processing and material parameters. On the processing front, soak time and pull rate have been identified as two key controlling factors for weight pickup and thickness uniformity. On the material front, amounts of dispersant and adhesion promoter were found to be crucial to slurry suspension and interlayer adhesion. A series of tests were conducted to identify the combination of these four parameters that can yield the optimum interlayer.

The initial tests showed no solvent penetration though the substrate wall. However, there was a small gradient in the slurry density within the dipping reservoir, indicating non-uniformity of the slurry. In addition, the slurry running along the IC masking tape caused build up of slurry at the closed end defect.

A second set of designed experiments was performed to quantify the effects of soak time, pull rate, slurry composition, and any interaction of these factors on coating weight, coating thickness and uniformity along tube axis. Ten groups of three tubes each were used. The groups were tested at three different settings of the inputs for pull rate and soak time. The tubes were dipped at the specified parameters, dried in a vertical drying oven, and measured for the coating weight and thickness.

Coating weight was found to be very consistent within each test group identified. As expected, the coating weight and thickness was proportional to the amount of soak time. However, a nonlinear relationship suggested a maximum achievable coating weight (saturation weight) which is likely determined by the substrate surface properties, slurry adhesion properties, and slurry viscosity. Interestingly, the pull rate showed an insignificant effect on either the coating weight or thickness. Since the tubes were dipped vertically the uniformity of the coating thickness along the length of the tube was a large concern. Microanalysis showed the coating thickness at $60 \mathrm{~cm}$ from the closed end was comparable to that at $5 \mathrm{~cm}$; thus showing good coating uniformity.

Although encouraging results were obtained from the above tests, the coating weights were generally much higher than the target value and could not be readily lowered down by changing the soak time and/or pull rate. As a result, the slurry composition had to be adjusted. In addition to reducing the solid loading in the slurry, the effect of each additive on the coating quality was also evaluated. Also, forced air drying was also introduced to speed up the drying process and prevent the slurry from running down the cell and 
causing closed end defects. After the target weight was reached, three tubes were calcined, plasma-sprayed with electrolyte powder, and densified. No peeling of electrolyte was observed, indicating good interlayer adhesion. While the thickness of the interlayer was found acceptable, microanalysis revealed that the porosity appeared slightly lower than the desired level. While appearing low, an AC impedance test was conducted that showed the interlayer porosity was acceptable.

It should also be noted that for both CIL application techniques, there is a significant manual handling of the AE tubes. Since handling the AE tubes at this stage will damage the wet CIL, a drying step which removes the solvent is required. Historically, the cylindrical tubes were placed horizontally on a drying tray and dried in an oven. Although tubes could be effectively dried under this condition, defects occasionally occurred on the open and closed end regions due to reactions with the drying tray. A better drying technique was thus needed to effectively address this issue.

The approach taken was to develop and qualify a vertical drying process. To evaluate the vertical drying, a drying cabinet was designed and constructed, and different drying temperatures were tested. The cabinet used two forced air and was vented through a central ventilation system to remove solvent fumes. A matrix of drying conditions (time, temperature, loading time, ventilation rate, etc.) was evaluated. Vertical drying successfully eliminated the defects found in horizontal drying. An optimized time/temperature vertical drying process was defined.

Conclusion: Prototype systems have been successfully utilized to evaluate both roller coating and dip coating techniques for applying the interlayer. Both techniques require additional testing to better define processing conditions and to complete the comparative evaluation of the techniques. Samples have been prepared to perform testing to evaluate their electrical properties. In additions, conditions have been defined for the post treatment of the coated layer.

\section{TASK 1.3 - CELL EVALUATION AND PROCESS DEVELOPMENT}

Approach: The focus of this task was to confirm the anticipated electrical performance of the interlayer cell, and to identify the improvements required for the transition from pilot-scale to large-scale production. The evaluation of electrical performance of Delta8 cells, produced utilizing roller coating to apply the CIL, was used to validate the anticipated power enhancement calculated from the baseline tubular cells. Following that, the focus was shifted to the development of the production-friendly manufacturing processes for CIL application. Included in this effort was the parallel development of two techniques: roller coating and dip coating. The approach for the former was to evaluate roller coating through the use of vendors, while an in-house system was used to evaluate the latter for Delta8 interlayer application.

Results and Discussion: To demonstrate that the anticipated performance enhancement has being achieved, several cell tests were utilized in this study. Figure 1 shows the power density curves at $900^{\circ} \mathrm{C}$ for four different types of cells: 
A. With Cerium Oxide $\left(\mathrm{CeO}_{2}\right)$ interlayer and Yttria-Stabilized-Zirconia electrolyte (YSZ $E L)$, this "first-generation" tubular cell was used as the baseline for this project.

B. With CIL and Scandia-Stabilized-Zirconia electrolyte (ScSZ EL), this "secondgeneration" tubular cell was used to project the target cell performance that had to be achieved in this study. A direct comparison between A and B showed the benefit of employing new interlayer and electrolyte materials.

C. This tubular cell, which had the same materials as B but the CIL was applied by the new and improved roller coating technique, was used for a direct comparison between $B$ and $C$ to show the benefit of employing the new application technique.

D. This Delta8 cell, which had the same materials as C and the CIL was applied by a similar roller coating technique, was used to demonstrate the enhanced performance with the new geometry cell.

Clearly, the performance of the cell with $\mathrm{CIL}$ applied by the improved coating technique (Cell C) consistently exceeded the target value (Cell B). In comparison with the baseline (Cell A), approximately $40 \%$ power enhancement can be achieved at 0.7 volt and $900^{\circ} \mathrm{C}$ by using CIL, ScSZ EL, and the improved process. An even bigger benefit, approximately 2.25 times that of the baseline performance, can be realized by further incorporating the Delta8 design (Cell D).

Power Density vs Voltage at $900^{\circ} \mathrm{C}$

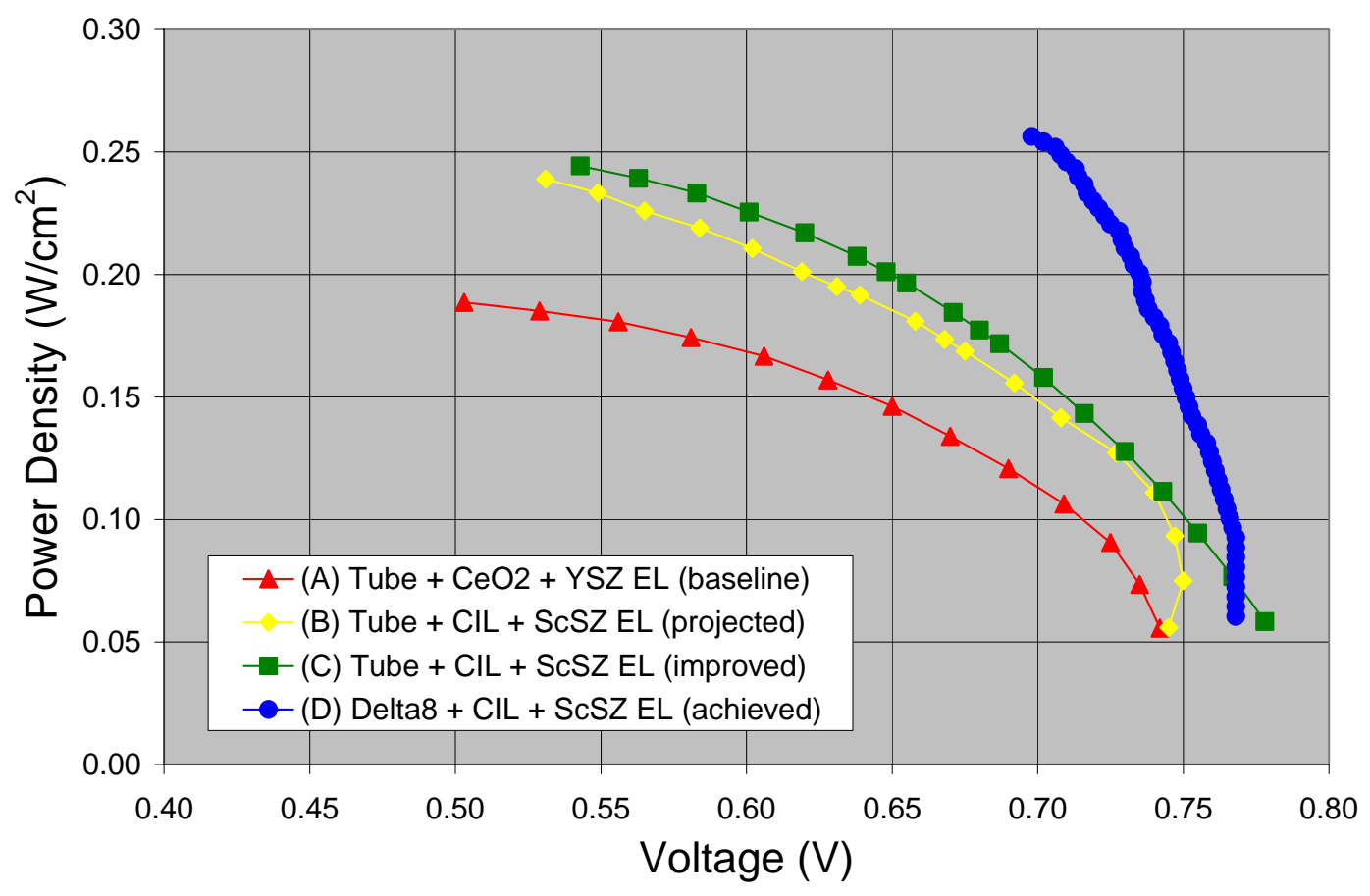

Figure 1 - Power Density vs. Voltage Curves at $900^{\circ} \mathrm{C}$ 
Since the use of ScSZ EL and CIL showed better performance than that of YSZ EL and $\mathrm{CeO}_{2}$ interlayer based on the tubular cells results in Figure 1, all Delta8 cells were made with the former components. As a result, there was no Delta8 cell with YSZ EL and $\mathrm{CeO}_{2}$ interlayer available for a similar comparison to show these benefits in the Delta8 format. There was no benefit to apply CIL to the Delta8 cells using techniques with known issues on tubular cells. Therefore, the best alternative was to test a tubular cell with dipped CIL and compare it to that with rolled CIL which was the baseline. As shown in Figure 2, the V-J curve of this cell was comparable to that of a cell with rolled CIL and was clearly well above the baseline. This demonstrated that no compromise in performance was made by using the DC process, thereby validating its effectiveness. More encouragingly, both Delta8 and tubular cells with dipped CIL showed comparable half-cell AC impedance. For example, the impedance data for the former at 1000, 950, and $900^{\circ} \mathrm{C}$ were $0.313,0.456$, and $0.704 \mathrm{ohm}^{\star} \mathrm{cm}^{2}$, respectively, while that for the latter were $0.364,0.513$, and $0.775 \mathrm{ohm}^{*} \mathrm{~cm}^{2}$, respectively. Since the half-cell AC impedance is an excellent indicator for the actual cell performance, it can be stated with a high degree of confidence that the Delta8 cell with dipped CIL will also perform well. At the time of preparing this report, preparation for testing of Delta8 cells with dipped IL was in progress.

For process development, a semi-automated roller coating machine, as shown in Figure 3 , was used to demonstrate its manufacturability. All the results were satisfactory except the less-than-100\% coating coverage. This was attributed to the use of out-ofspecification Delta8 substrates. Based on the potential for mass manufacturing, this approach was pursued further and is discussed in Section 1.4.

Significant progress was also made in the development of the in-house dip coating process. As shown in Figure 4, a new dipping tank, slurry circulation system, and forced-air drying mechanism were designed and built specifically for the Delta8 geometry. The dip coating of the Delta8 substrate showed very encouraging results, including the anticipated $100 \%$ coverage as well as limited thickness variations in peakto-valley and end-to-end positions, as confirmed in microanalysis. As mentioned previously, the Delta8 cell with CIL applied using this new system has shown the same excellent Half-cell AC impedance obtained from its tubular counterparts. 


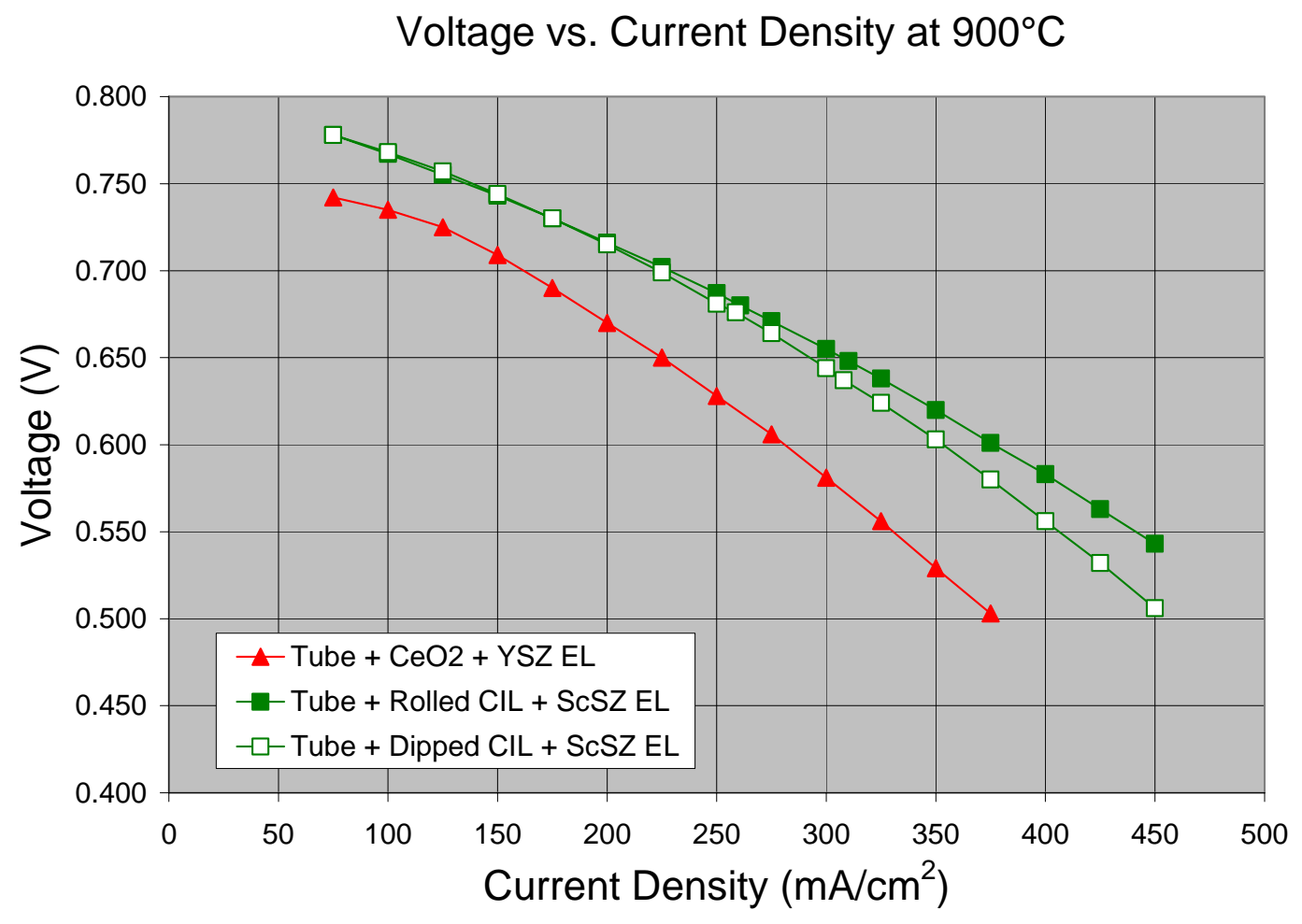

Figure 2 - Voltage vs. Current Density Curves at $900^{\circ} \mathrm{C}$



Figure 3 - Roller Coating Machine for Applying Interlayer to Delta8 Cells 


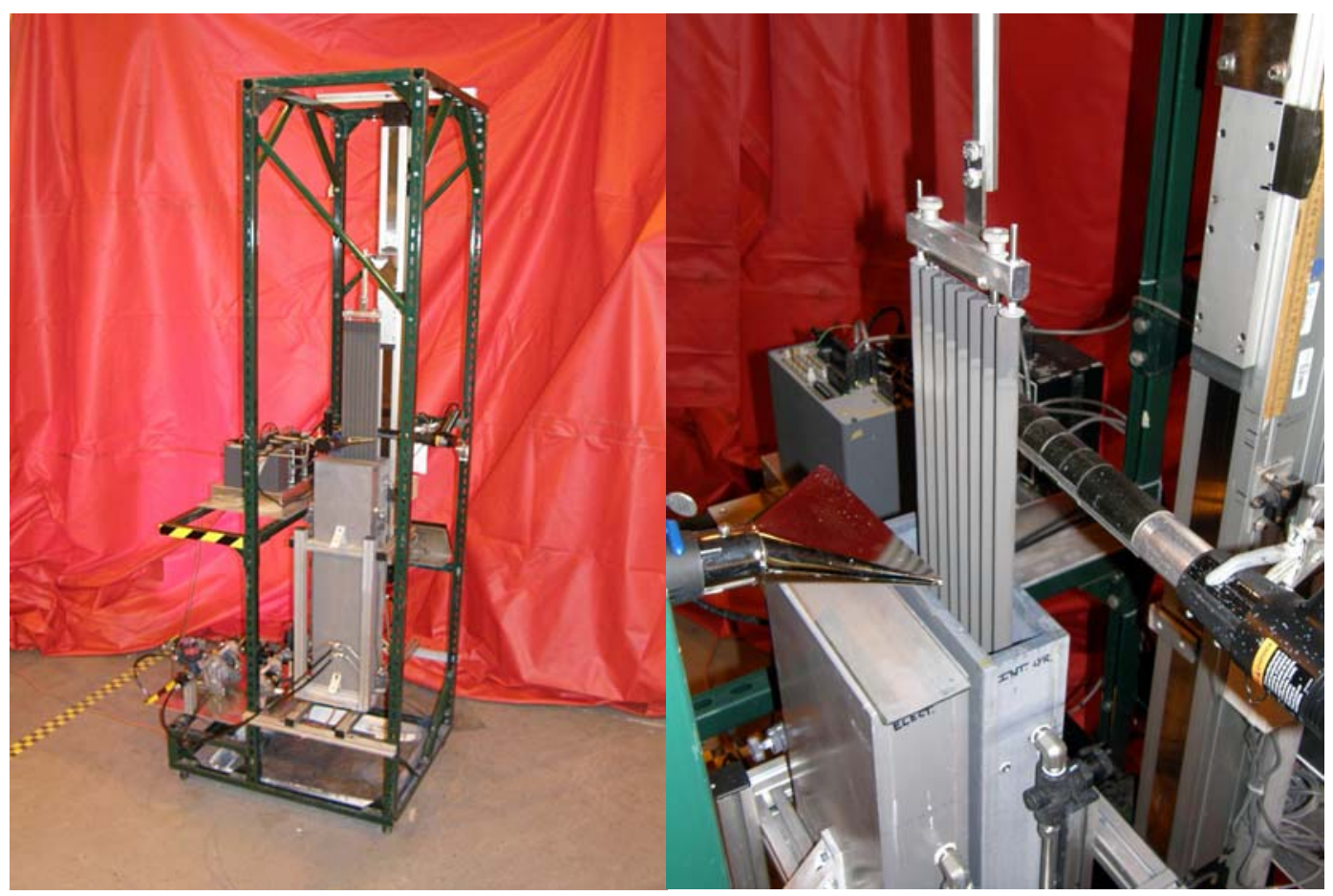

Figure 4 - Dip Coating System for Applying Interlayer to Delta8 Cells

Conclusions: The enhanced electrical performance has been successfully demonstrated for the CIL and ScSZ EL system using Delta8 cells. Meanwhile, the prototype dipping system was built and tested, producing Delta8 cells which showed excellent half cell AC impedance. In addition, the vendor roller coating systems which have shown the potential for rapid processing warrant further evaluation.

\section{TASK 1.4 - EQUIPMENT DESIGN}

Approach: The objective was to design production-friendly equipment for the composite interlayer (CIL) application. The two selected application techniques, roller coating and dip coating, were tested and compared to determine the preferred process. The choice of the technique was based on (1) the practical limitation of each technique and its likelihood for mass production, (2) the quality of the end product, including coating uniformity and cell performance, and (3) the throughput and cost.

Results and Discussion: Multiple roller coating trials were conducted at vendor sites. Due to the lack of in-spec Delta8 substrates, rejected products with dimensional issues were used in this study. While all coated cells met weight pickup requirements, only six out of eight Delta8 cells survived the coating process with no visible damage.

To evaluate the coating uniformity, one cell was sectioned and the interlayer thickness was determined by microanalysis. Except for the two outside edges, most areas were successfully coated. The coating at the peak was significantly thinner than that at the valley. For comparison, a similar microanalysis was performed on a cell with interlayer 
applied by dip coating. There was no discernable peak-slope-valley dependence with dip coating indicating a very uniform coating across the width of the Delta8 cell. Since this cell was dipped vertically with the open end up, a running of the interlayer slurry toward the closed end was a big concern. To evaluate this, the cell was also sectioned at three different locations (closed end, mid-length, and open end). Again, there is no discernable axial location dependence indicating a very uniform coating across the length of the Delta8 cell. The data thus shows that, with the present dimensional variations with the Delta8 cell, the dip coating will produce a more uniform coating.

To evaluate the effect of interlayer application technique on cell performance, two halfcell AC impedance tests, which are good predicators for electrical performance, were conducted. The impedance values for the cell with dip-coated interlayer are lower than that with roller-coated interlayer at all three temperatures. Granted that the data are limited and each technique might not have been optimized, there is certainly no evidence to suggest that the electrical performance of a cell with interlayer applied by dip coating shall be inferior to its roller-coated counterpart.

An analysis on throughput and cost was also performed for each technique. While the coating time for roller coating is estimated to be at least an order-of-magnitude less than that for dip coating, the actual throughput is essentially the same since the preparation time for coating, which is the same for both techniques, is the rate-limiting step. In terms of cost, the result of this analysis showed that the higher labor cost associated with dip coating was compensated by the higher ink making cost for roller coating; therefore, their overall costs were very comparable.

With comparable throughput, cost, and cell performance, it is evident that the unmatchable strength of dip coating is its independence of substrate geometry which by default guarantees $100 \%$ coating coverage and $0 \%$ cell breakage. Roller coating would have been a competitive technique for substrates with tight dimension tolerance; however, at the present time, it is not deemed the path of choice due to the apparent substrate issue. As a result, the decision was made to adopt the dip coating technique for mass production.

Conclusions: Dip coating is selected as the technique of choice for applying the composite interlayer to the Delta8 cell. While the test result of the Delta8 cell is still pending at the time of preparing this report, it is highly confident that good performance will be obtained based on the tubular cell tests and impedance results. Its technical readiness and product quality have been successfully and repeatedly demonstrated and its throughput and cost are amenable to large scale manufacturing. The blueprint of the prototype system shall be used as the foundation of the equipment specification for mass production. 



\section{Task 2.0 - 5 kWe System Testing}

Approach: The objective of this task was to build and install two fully integrated $5 \mathrm{kWe}-$ class SOFC power systems for the purpose of testing and evaluating state-of-the-art cell and bundle technologies, advanced generator and module design features, balance-ofplant components, and cost reduction measures. System testing was performed to:

- Evaluate cell, bundle, and system performance

- Assess new materials, cell manufacturing processes, components, and subsystems in a generator environment

- Define the acceptable operating envelope (temperature, startup, shutdowns, transients, etc.)

- Generate data to validate computer-based models

- Determine the long term effects of startups, shutdowns, and transients between power levels

- Investigate the reliability of balance-of-plant systems and components

- Assess new technologies for monitoring and controlling future SOFC systems

- Provide operational experience for the host site operators.

Each of the two $5 \mathrm{kWe}$-class SOFC power systems were operated at a host site to assess cells, bundles, generator components, and BOP systems in a 'real-world' environment.

Results and Discussion: This task was divided into three subtasks. Subtasks 2.1 and 2.2 encompass the design, assembly, installation, and operation of a $5 \mathrm{kWe}$-class SOFC power system at the Siemens Energy Turbine-Generator Plant located in Charlotte, NC. Under Subtask 2.3 a second 5 kWe-class SOFC power system was installed and operated at the Phipps Conservatory and Botanical Garden, Pittsburgh, PA.

SFC remotely monitored both systems from its facility in Pittsburgh, PA and also provided operational support and data analysis to on-site personnel.

\section{TASK 2.1 - 5 KWE SYSTEM ASSEMBLY - NORTH CAROLINA}

Cell and Bundle Manufacturing: The cells to be utilized in this task are the Siemens tubular SOFC, $2.2 \mathrm{~cm}$ in diameter with an active length of $75 \mathrm{~cm}$. Cells for the NC 5 kWe system were manufactured using state-of-the-art atmospheric plasma spray for the electrolyte, interconnection, and fuel electrode. The cells were assembled into bundles using foam-top nickel screens for the cell-to-cell electrical connection. Each bundle consisted of eleven rows of cells with two cells per row. After sintering, the bundles passed all quality control checks and were transferred to module assembly. 
Module Assembly: The SOFC module was assembled following established procedures and schedule. Upon completion, the module passed all quality control checks and was integrated with the balance-of-plant.

Balance-of-Plant: The balance-of-plant (BOP) utilized in this task was provided by a SFC-qualified subcontractor and was accepted and approved for use after passing a series of quality control procedures.

System Assembly: The SOFC module and BOP were successfully integrated to form the NC $5 \mathrm{kWe}$ SOFC power system. The fully integrated $5 \mathrm{kWe}$ SOFC system was installed into a test station were it was subjected to pre-operational shakedown prior to delivery to the host site. The NC $5 \mathrm{kWe}$ SOFC power system, prior to delivery to the host site, is shown in Figure 5.

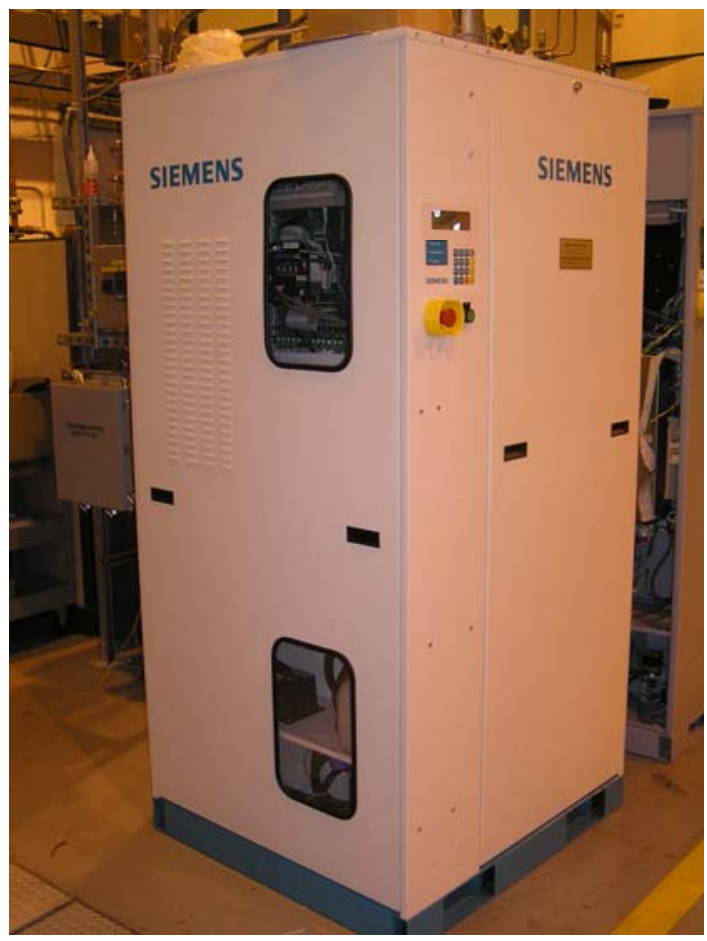

Figure 5 - 5 kWe SOFC System prior to delivery to the host site

\section{TASK 2.2 - 5 KWE INSTALLATION, STARTUP AND OPERATION - NORTH CAROLINA}

The $5 \mathrm{kWe}$ SOFC power system was delivered to the Siemens Energy TurbineGenerator Plant, 5101 Westinghouse Blvd, Charlotte, NC via a commercial over-theroad carrier. The lack of an easily accessible high pressure natural gas source necessitated the installation of a natural gas compressor. Other modifications to the site included installation of a longer than expected exhaust system and a dedicated internet line for remote communications. 
SFC personnel installed the system without any complications. During a pre-start inspection and shakedown, it was discovered that site personnel incorrectly installed the system batteries which led to damage of the main inverter, the auxiliary inverter, and the auxiliary battery charger. Replacement parts were obtained and the necessary repairs completed by SFC personnel. The system was then subjected to a thorough pre-start verification and shakedown procedure to ensure all BOP and module components were operating properly. Due to a faulty DC power supply, the shakedown procedure was unable to simulate the export of the system's AC power to the grid.

Startup of the system was subsequently initiated and DC power drawn from the SOFC module. The inverter successfully connected and synchronized with the AC grid but was unable to control the AC output to the grid, allowing only the export of the system's full power. Startup was aborted, the inverter removed, and returned to the manufacturer for repair.

The inverter was repaired and returned by the manufacturer and its performance verified via bench testing in Pittsburgh.

The North Carolina 5 kWe SOFC system was originally scheduled for installation and startup in 2QCY09. However, due to the manufacturing, BOP, and site installation issues as of the end of the period of performance of this project, the system had not been fully operational.

\section{TASK 2.3 - 5 KWE INSTALLATION, STARTUP, AND OPERATION - PHIPPS CONSERVATORY AND BOTANICAL GARDENS}

A 5 kWe-class SOFC power system was delivered to the Phipps Conservatory and Botanical Gardens, Pittsburgh, PA. Fueled by natural gas, the fully integrated power system was designed to produce nominally $3 \mathrm{kWe}$ of $\mathrm{AC}$ power for on-site consumption and deliver thermal energy in the form of hot water to the site. The system includes all hardware, instrumentation and controls, and software needed for system startup, operation, planned shutdowns, and safe unplanned shutdowns. After manned startup, the system operated unattended, with automatic remote monitoring via telecommunications links.

The system integrates an SOFC module with a balance-of-plant to form a fully integrated power system. The SOFC module consists of four bundles, each incorporating 22 tubular solid oxide fuel cells, each measuring $2.2 \mathrm{~cm}$ in diameter with an active length of $75 \mathrm{~cm}$. The module was manufactured by SFC at its Churchill, PA facilities using atmospheric plasma spray technology. The module contains the state-of-the-art cell-tocell and bundle-to-bundle technologies, respectively, and incorporates other advanced generator and module design features and cost reduction measures. Incoming desulfurized pipeline natural gas is reformed internally within the module. The internal reformation process does not require external equipment, external energy supply or external water except during startup.

The system's balance-of-plant, purchased from a subcontractor, includes the following major subsystems: 
- Electronic control system

- Air supply system

- Fuel supply system and desulfurizer

- Module purge system

- $\quad$ Start-up steam supply system

- SOFC module heaters

- Heat recovery system

- $\mathrm{DC}$ to AC power conversion system.

The SOFC 5 kWe SOFC power system is depicted schematically in Figure 6.

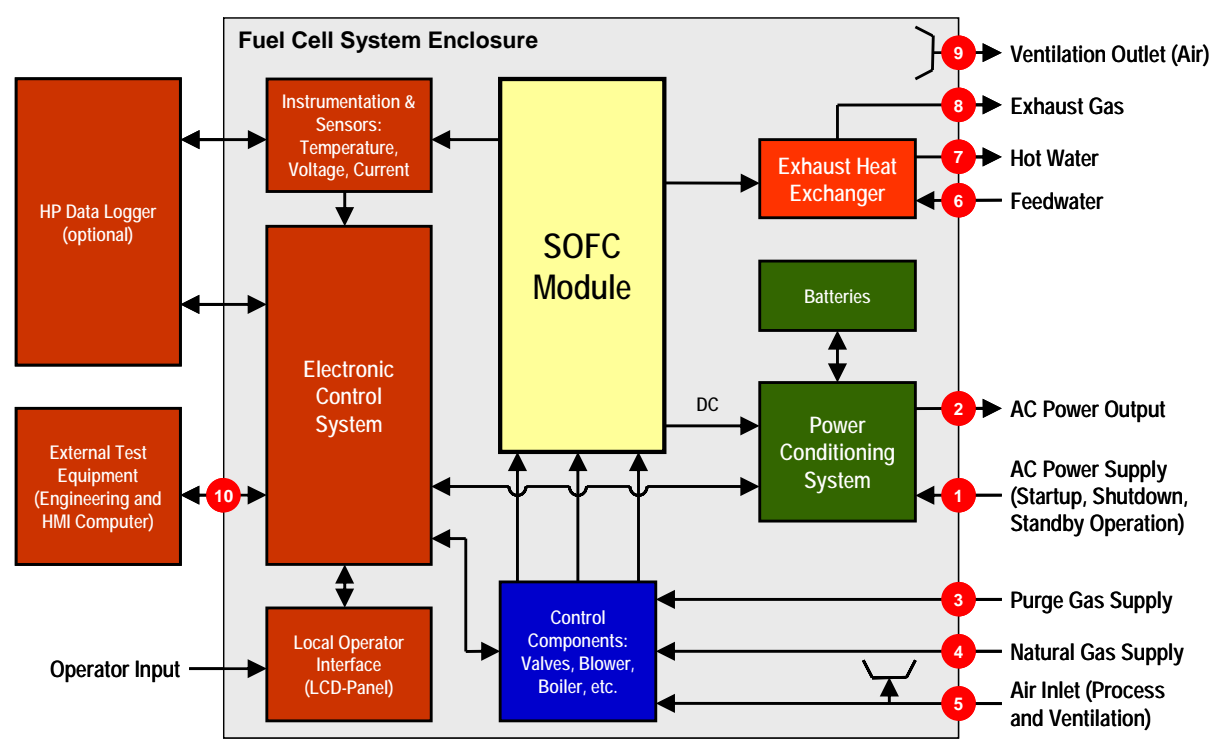

Figure 6 - SOFC System Schematic Diagram

A number of site visits and meetings between SFC and site personnel, respectively, resulted in an installation that went smoothly and had no significant incidents. Following the uneventful installation and operational checkout the system was successfully started without incident. Figure 7 shows the system installed at the Phipps Conservatory.

The system was successfully started on December 8, 2006 and after steady-state conditions were achieved the system was transitioned into the power dispatch mode. As of the end of the period-of-performance for this project the system had accumulated more than $17,590 \mathrm{hrs}$ of operation. An operational summary is presented in Table 1 and a lifetime plot in Figure 8. 


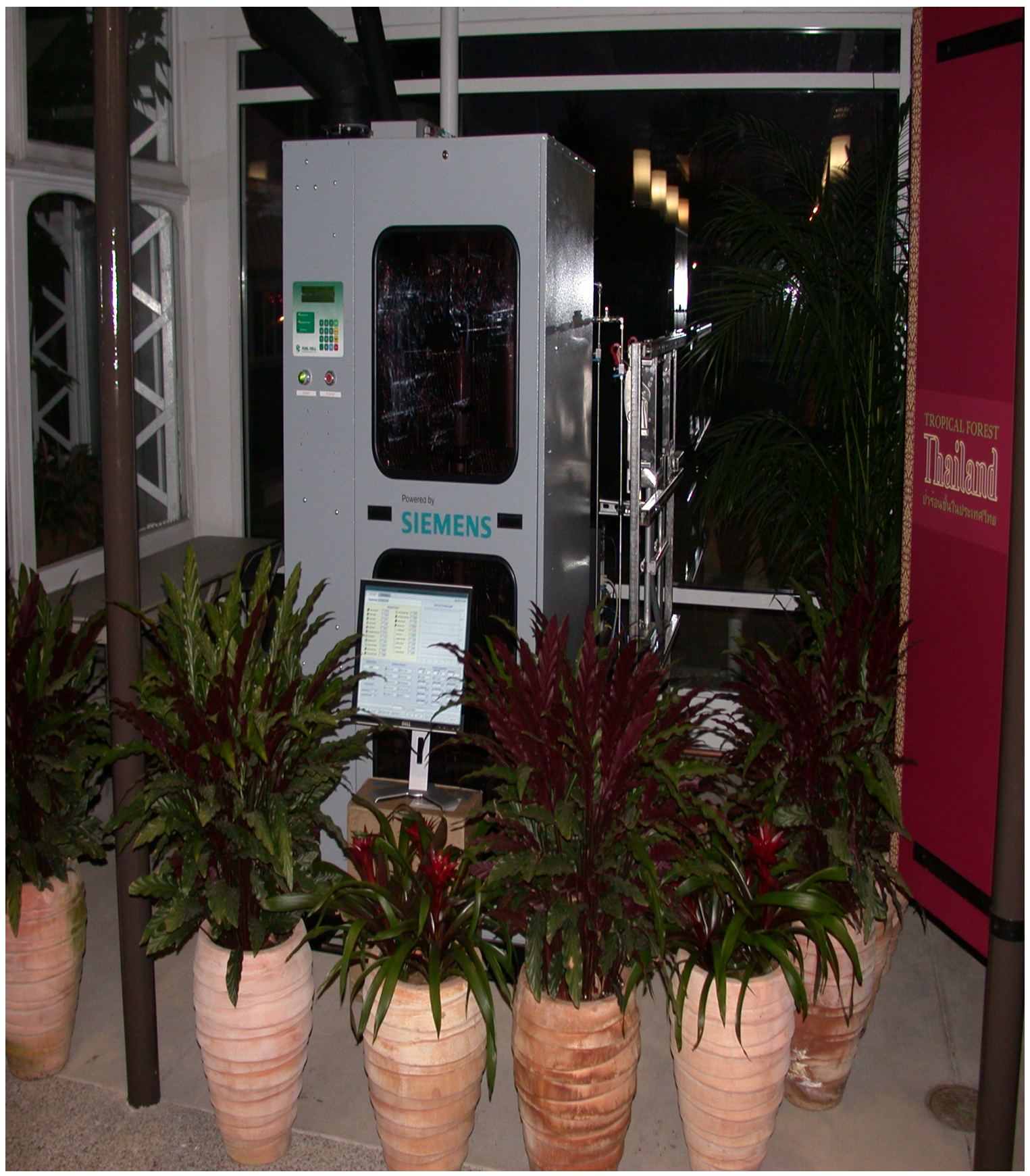

Figure 7 - The 5 kWe-class SOFC Power System Installed at the Phipps Conservatory 
Table 1- Phipps 5 kWe SOFC Power System Performance Summary as of March 31, 2009

\begin{tabular}{|l|l|}
\hline Started & 8-Dec-2006 \\
\hline Total Run Time [hrs] & 17,590 \\
\hline Stack Temperature [deg C] & 970 \\
\hline Stack Voltage [V]; average & 28.1 \\
\hline Stack Current [amps]; average & 109.0 \\
\hline Stack Power [kWe DC]; average & 3.04 \\
\hline Net AC Power [kWe]; average & 2.19 \\
\hline Total Energy Produced [MWh, AC] & 37.6 \\
\hline Electrical Efficiency, net AC [\%] & 33.6 \\
\hline Availability [\%] & 85.5 \\
\hline
\end{tabular}

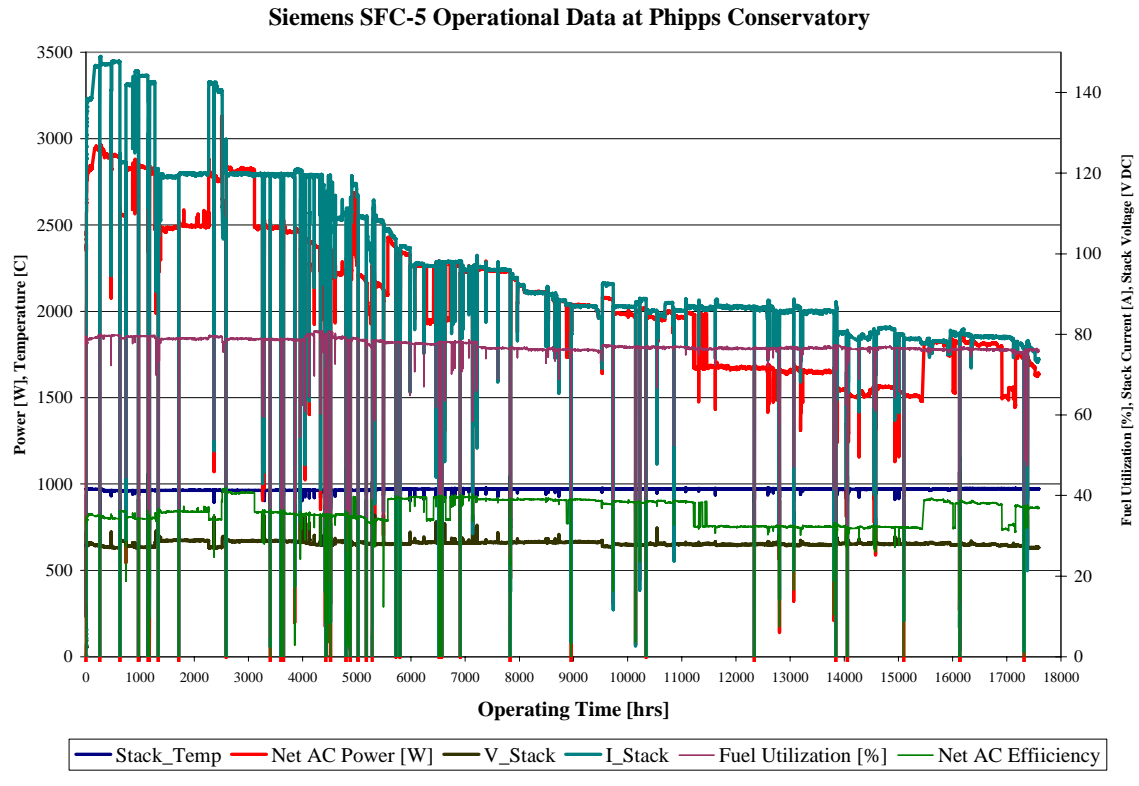

Figure 8 - Lifetime plot of the Phipps SFC-5 SOFC system 
During normal operation the system delivered on average $2.2 \mathrm{kWe}$ AC for on-site consumption and thermal energy in the form of hot water to the site's tepid watering system. Operation was typically autonomous, requiring minimal operator intervention, and achieved an overall availability of $>85 \%$. Over the period of operation routine maintenance included replacing the desulfurizer catalyst, air filter replacement, water tank refill, replacement of NHMix p-banks, and inspection of the water condensate from the exhaust line. No repairs to the stack, module, or balance-of-plant were required.

Very few reliability issues were encountered despite harsh operating conditions. The ambient environment was hot, humid, and dirty due to location of the system; a high foot-traffic area leading into Phipps' Tropical Forest Conservatory. System upsets, or offloads, were primarily due to an unstable local grid within the Conservatory.

Early in the operation, after a number of current offloads were experienced, it was theorized many of the upsets were a result of either communications problems, an internal fault with the inverter, and/or grid disturbances. Many of the early outages were determined to be due to localized power outages associated with construction at the Conservatory.

To determine why the inverter dropped its load so frequently, a Dranetz power quality analyzer with automated data triggering and capture capabilities was installed on the output power grid. The data retrieved from the analyzer indicated the inverter was reacting to grid voltage sags as much as $70-80 \mathrm{~V}$ that last between $100-200$ miliseconds (ms), which is within the manufacturer's design specifications. Discussions with the manufacturer have resulted in an improvement to the next generation of inverters that will not be as sensitive to grid disturbances. The new inverters were desensitized to disconnect from the grid during small grid disturbances in approximately $1 \mathrm{~s}$ instead of $100 \mathrm{~ms}$, while remaining compliant with UL 1741 standard (which allows up to $2 \mathrm{~s}$ to disconnect). It was neither possible nor feasible to retrofit a new inverter into the Phipps $5 \mathrm{kWe}$ system. It is anticipated that the new inverter will reduce the number of current off-loads by more than $90 \%$.

The 5 kWe SOFC system has no energy storage available on board as the batteries are maintained in a nearly fully charged mode. Thus when power cannot be exported to the grid, it must be reduced quickly and the system transitions form Grid-Tie (GT) to GTStandby, reducing generator power to either zero or minimum level to support the BOP parasitic loads. Although SFC operators were notified about each disturbance via internet based alarm notification, when the system detected the grid had returned, it reloaded autonomously, without the need for outside intervention.

During the more than two years of operation the system also experienced two weather related outages, one lasting as long as three days. Since the system is not designed to operate independently from the grid the system shutdown; a consequence of it not being able to sustain its temperature while producing power solely to support the BOP parasitics. During both outages routine maintenance procedures were performed and subsequently the system was restarted without incident. 
The Phipps 5 kWe SOFC power system continues to operate reliably and efficiently and continues to experience power grid disturbances (on the order of bi-weekly) that cause the system to off-load and automatically reload.

\section{Future Work:}

NC 5 kWe SOFC Power System: The repaired inverter will be installed in the system. Additional pre-operation diagnostics will be performed to determine if the reverse wiring of the batteries resulted in any previously undiscovered damage to the module and BOP. Startup and operation of the system is planned but not scheduled.

Phipps 5 kWe SOFC Power System: Future activities will be limited to remote monitoring and data analysis, routine maintenance, and installation of a new water mass flowmeter that will allow accurate measurement of the thermal energy exported to the site. 


\section{Task 3.0 - Project Management}

All program deliverables were prepared and submitted as required.

Program spending exceeded the original budget; cost overruns were absorbed By SFC increasing cost share from $52 \%$ to $56 \%$ of the total project costs. The increased nonfederal portion of the project costs is reflected in the Q6 costs, shown in Table 2. All authorized Federal funds were costed and within the federal budget. Due to the aforementioned delays in the North Carolina $5 \mathrm{kWe}$ system, Tasks 2.1 and 2.2 were significantly behind schedule. As a result, the system did not achieve full operation within the period of performance of this contract.

All major milestones were achieved except for the startup of the North Carolina $5 \mathrm{kWe}$ SOFC Power System, Table 3. The status of the NC $5 \mathrm{kWe}$ system is presently under discussion with DOE, the host site, and SFC. 
Table 2 - Project Spending

\begin{tabular}{|c|c|c|c|c|c|c|c|c|c|c|}
\hline \multirow[t]{2}{*}{ Baseline Reporting Quarter } & \multicolumn{4}{|c|}{ Year 1 09/12/06 - 09/30/07 } & \multicolumn{4}{|c|}{ Year 2 10/01/07 - 09/30/08 } & \multicolumn{2}{|c|}{$\begin{array}{c}\text { Year } 3 \\
\text { 10/01/08 - 03/05/09 }\end{array}$} \\
\hline & $\mathbf{Q 1}$ & $\mathbf{Q}$ & $\mathbf{Q 3}$ & Q4 & Q̧ & Q6 & Q7 & Q8 & $\mathbf{Q 9}$ & Q10 \\
\hline \multicolumn{11}{|l|}{ Baseline Cost Plan } \\
\hline Federal Share & $\$ 494,440$ & $\$ 77,443$ & $\$ 67,532$ & $\$ 88,528$ & $\$ 201,082$ & $\$ 0$ & $\$ 0$ & $\$ 0$ & $\$ 0$ & $\$ 0$ \\
\hline Non-Federal Share & $\$ 443,189$ & $\$ 537,720$ & $\$ 0$ & $\$ 7,809$ & $\$ 0$ & $\$ 202,026$ & $\$ 0$ & $\$ 0$ & $\$ 0$ & $\$ 0$ \\
\hline Total Planned - Quarterly (Federal and Non-Federal) & $\$ 937,629$ & $\$ 615,163$ & $\$ 67,532$ & $\$ 96,337$ & $\$ 201,082$ & $\$ 202,026$ & $\$ 0$ & $\$ 0$ & $\$ 0$ & $\$ 0$ \\
\hline Oumuative Baseline Cost & $\$ 937,629$ & $\$ 1,552,792$ & $\$ 1,620,324$ & $\$ 1,716,661$ & $\$ 1,917,743$ & $\$ 2,119,769$ & $\$ 2,119,769$ & $\$ 2,119,769$ & $\$ 2,119,769$ & $\$ 2,119,769$ \\
\hline \multicolumn{11}{|l|}{ Actual Incurred Costs } \\
\hline Federal Share & $\$ 184,646$ & $\$ 105,253$ & $\$ 149,860$ & $(\$ 8,288)$ & $\$ 44,815$ & $\$ 310,155$ & $\$ 142,583$ & $\$ 0$ & $\$ 0$ & $\$ 0$ \\
\hline Non-Federal Share & $\$ 869,996$ & $\$ 116,568$ & $\$ 23,728$ & $\$ 7,477$ & $\$ 2,888$ & $\$ 0$ & $\$ 14,538$ & $\$ 155,549$ & $\$ 0$ & $\$ 0$ \\
\hline Total Inaurred- Quarterly(Federal and Non-Federal) & $\$ 1,054,642$ & $\$ 221,821$ & $\$ 173,588$ & (\$811) & $\$ 47,703$ & $\$ 310,155$ & $\$ 157,121$ & $\$ 155,549$ & $\$ 0$ & $\$ 0$ \\
\hline Oumuative Incurred Cost & $\$ 1,054,642$ & $\$ 1,276,463$ & $\$ 1,450,051$ & $\$ 1,449,240$ & $\$ 1,496,943$ & $\$ 1,807,098$ & $\$ 1,964,219$ & $\$ 2,119,768$ & $\$ 2,119,768$ & $\$ 2,119,768$ \\
\hline \multicolumn{11}{|l|}{ Variance } \\
\hline Federal Share & $\$ 309,794$ & $(\$ 27,810)$ & $(\$ 82,328)$ & $\$ 96,816$ & $\$ 156,267$ & $(\$ 310,155)$ & $(\$ 142,583)$ & $\$ 0$ & $\$ 0$ & $\$ 0$ \\
\hline Non-Federal Share & $(\$ 426,807)$ & $\$ 421,152$ & $(\$ 23,728)$ & $\$ 332$ & $(\$ 2,888)$ & $\$ 202,026$ & $(\$ 14,538)$ & $(\$ 155,549)$ & $\$ 0$ & $\$ 0$ \\
\hline Total Variance - Quarterly (Federal and NonFederal) & $(\$ 17,013)$ & $\$ 393,342$ & $(\$ 106,056)$ & $\$ 97,148$ & $\$ 153,379$ & $(\$ 108,129)$ & $(\$ 157,121)$ & $(\$ 155,549)$ & $\$ 0$ & $\$ 0$ \\
\hline Oumulative Variance & $(\$ 17,013)$ & $\$ 276,329$ & $\$ 170,273$ & $\$ 267,421$ & $\$ 420,800$ & $\$ 312,671$ & $\$ 155,550$ & $\$ 1$ & $\$ 1$ & $\$ 1$ \\
\hline Comments & 1 & 2 & 2 & $2,3,4$ & 2 & 2,5 & 2,5 & 5,6 & 7 & 7 \\
\hline
\end{tabular}

\section{Comments}

1. Variance due to delay in cell manufacturing (Federal Share) and recognition of pre-amard spend (Non-Federal Share)

2. Delay inmanufacture and assembly of $5 \mathrm{kWesystem}$ (Federal Share)

3. Contract amendment $\# 01$ added $\$ 29,032$ Federa Share and $\$ 7,809$ Non-Federal Share

4. Reversed cell manufacturing costs incurred in $@$ due to quality issues

5. Contract amendment $\# 002$ added $\$ 202,026$ Non-Federal Share to reflect project cost overnuns.

6. Delay in installationand startup of the $5 \mathrm{kWe}$ system (Non-Federal Share)

7. All authoized Federal funds have been costed, cost share obligation has been saisifed 
Table 3 - Major Milestones

\section{DOE North Carolina Project \#42810}

Period of Performance 9/6/06 - 3/5/09

Milestone Status Report - March 2009

\begin{tabular}{|c|c|c|c|c|}
\hline $\begin{array}{l}\text { Task } \\
\text { Number }\end{array}$ & Milestone & $\begin{array}{l}\text { Planned } \\
\text { Completion }\end{array}$ & $\begin{array}{l}\text { Actual } \\
\text { Completion }\end{array}$ & Comments \\
\hline 1.1 & Select two candidate interlayer application techniques. & $12 / 31 / 2006$ & Dec-06 & \\
\hline 2.3 & $\begin{array}{l}\text { Complete site installation and start up of } 5 \mathrm{kWe} \text { SOFC system at the Phipps } \\
\text { Conservatory and Botanical Gardens in Pittsburgh, PA }\end{array}$ & $1 / 30 / 2007$ & Dec-06 & \\
\hline 2.2 & Complete site installation and start up of $5 \mathrm{kWe}$ SOFC system in North & $6 / 30 / 2008$ & & Incomplete* \\
\hline 1.3 & Prepare SECA HPD Cell for cell testing and evaluation of interlayer application. & $6 / 30 / 2007$ & Jun-07 & \\
\hline 1.3 & Complete SECA HPD Cell test and evaluation. & $12 / 31 / 2007$ & Dec-07 & \\
\hline 1.4 & Complete design of interlayer fabrication equipment. & $5 / 31 / 2008$ & Jun-08 & \\
\hline
\end{tabular}

* - due to numerous delays, as described in the respective sections of this final report, the North Carolina 5 kWe SOFC System was not rendered fully operational within the period of performance of this project. 


\section{List of Acronyms and Abbreviations}

$\begin{array}{ll}\text { AE } & \text { Air Electrode } \\ \text { BOP } & \text { Balance-of-Plant } \\ \text { CIL } & \text { Composite Interlayer } \\ \text { DC } & \text { Dip Coating } \\ \text { DOE } & \text { U.S. Department of Energy } \\ \text { DRC } & \text { Direct Roller Coating } \\ \text { EL } & \text { Electrolyte } \\ \text { GT } & \text { Grid Tie } \\ \text { HPD } & \text { High Power Density } \\ \text { IC } & \text { Interconnection } \\ \text { IRC } & \text { Ink-roller-coating } \\ \text { kWe } & \text { Kilowatts, electric } \\ \text { NHMIX } & \text { Reducing gas consisting of mixture 95\% nitrogen / 5\% hydrogen } \\ \text { ScSZ } & \text { Scandia-Stabilized Zirconia } \\ \text { SECA } & \text { Solid State Energy Conversion Alliance } \\ \text { SFC } & \text { Stationary Fuel Cells } \\ \text { SOFC } & \text { Solid Oxide Fuel Cell } \\ \text { UL } & \text { Underwriters Laboratory } \\ \text { YSZ } & \text { Yttria-Stabilized Zirconia }\end{array}$

